\title{
Evaluation of real-time PCR for diagnosis of Bordetella pertussis infection
}

\author{
Laina Knorr ${ }^{1}$, Julie D Fox*1,3, Peter AG Tilley ${ }^{1,3}$ and Jasmine Ahmed-Bentley ${ }^{2}$
}

\author{
Address: ${ }^{1}$ Provincial Laboratory for Public Health, Calgary, Alberta, Canada, ${ }^{2}$ Department of Medical Microbiology, University of Alberta, \\ Edmonton, Alberta, Canada and ${ }^{3}$ Department of Microbiology and Infectious Diseases, University of Calgary, Alberta, Canada \\ Email: Laina Knorr - laina88@sasktel.net; Julie D Fox* - J.Fox@provlab.ab.ca; Peter AG Tilley - P.Tilley@provlab.ab.ca; Jasmine Ahmed- \\ Bentley - Jasmine.Ahmed-Bentley@mdsmetro.com \\ * Corresponding author
}

Published: 23 March 2006

BMC Infectious Diseases2006, 6:62 doi:10.1 186/147I-2334-6-62

This article is available from: http://www.biomedcentral.com/I47I-2334/6/62

(C) 2006Knorr et al; licensee BioMed Central Ltd.

This is an Open Access article distributed under the terms of the Creative Commons Attribution License (http://creativecommons.org/licenses/by/2.0), which permits unrestricted use, distribution, and reproduction in any medium, provided the original work is properly cited.
Received: 30 November 2005

Accepted: 23 March 2006

\begin{abstract}
Background: Nucleic acid amplification of the IS48I region by PCR is more sensitive than culture for detection and diagnosis of Bordetella pertussis but the assay has known cross-reactivity for Bordetella holmesii and its use as a routine diagnostic assay has not been widely evaluated.

Methods: The objectives of this study were: I) to assess the diagnostic utility of real-time IS48I PCR by comparison of results with culture and direct fluorescent antigen (DFA) testing for $B$. pertussis, 2) to employ a PCR assay designed against a different insertion sequence (ISIO0I) to assess the incidence of $B$. holmesii in symptomatic individuals and 3 ) to design and evaluate a new PCR-based assay which could be used for B. pertussis confirmation. A total of 808 nasopharyngeal specimens were included in the study the majority of which were submitted in charcoal transport medium (88\%) with the rest submitted in Regan-Lowe medium.

Results: Concordant results for PCR, DFA and culture were obtained for $2 \mathrm{I} B$. pertussis positive and $729 \mathrm{~B}$. pertussis negative specimens. DFA was prone to false positive and negative reactions when compared with both PCR and culture. The IS48I PCR identified 28 positive results for specimens that were DFA and culture negative. A novel real-time PCR targeting the $B$. pertussis toxin promoter was found to be specific and useful for confirming the majority of IS48I positive specimens as $B$. pertussis. B. holmesii was not detected in any of the submitted samples.

Conclusion: The potential pick up of B. holmesii by the IS48I PCR had minimal diagnostic relevance in the Alberta population during the time period of our study. The IS48I PCR assay is now used in our laboratory routinely for front-line screening of samples for $B$. pertussis with associated enhancement in diagnostic sensitivity compared with DFA and culture. Retrospectively, patients' samples are batched and tested by the ISI00I MB and TPR assays for research purposes and to ensure there is no change in $B$. holmesii incidence in the population.
\end{abstract}

\section{Background}

The etiologic agent of whooping cough is Bordetella pertussis. Diagnosis at an early stage of illness is desired to institute therapy and prevent transmission. Pertussis-like respiratory illness can also be caused by other Bordetella species including parapertussis [1], bronchiseptica [2] and holmesii $[3,4]$. Currently available $B$. pertussis diagnostic methods include culture, direct fluorescent antigen (DFA) 
tests, serology and nucleic acid amplification assays such as the polymerase chain reaction (PCR). The first publication of $B$. pertussis PCR was in 1989 [5]. Since then numerous protocols have been reported targeting different bacterial genes. B. pertussis PCR can be applied directly to nasopharyngeal specimens, is more sensitive than culture, can detect nonviable organisms and results using this method can be obtained rapidly. Thus, this diagnostic approach has the potential to improve our understanding of $B$. pertussis transmission and epidemiology, to allow us to measure accurately the impact on the community, as well as enhance studies of vaccine efficacy.

B. pertussis carries 50-100 copies of IS481 and therefore this should be a good target for development of a sensitive diagnostic assay when compared with other single-copy regions or genes. Indeed, IS481-based PCR has been shown to be more sensitive than one designed against the toxin promoter [6]. It has been shown that PCR assays targeting IS481 PCR are highly specific for B. pertussis and B. holmesii [7] and, in a real-time format, this approach enhances diagnostic utility above other methods. However, the potential detection of $B$. holmesii in cases of a pertussis-like illness could compromise appropriate management and compromise studies of vaccine efficacy [7].

In this study we aimed to assess the diagnostic utility of an IS481 real-time PCR assay [7], compare the PCR results to culture and DFA, assess the incidence of $B$. holmesii in the test population and develop and apply a novel real-time PCR assay against the toxin promoter region for specific detection (and thus confirmation) of B. pertussis infection.

\section{Methods}

\section{Bacterial strains}

All bacteria used for the study were from standard cultures grown at $35^{\circ} \mathrm{C}$ in ambient atmosphere on Regan-Lowe media (Daylnn Biologicals Inc., Calgary, AB). B. pertussis, $B$. holmesii, B. bronchiseptica and B. parapertussis cultures were suspended in sterile saline at a concentration equivalent to $10^{8} \mathrm{cfu} / \mathrm{ml}$, based on McFarland turbidimetric standards.

\section{Processing of specimens}

Consecutive nasopharyngeal (NP) specimens received during $2003(\mathrm{n}=204)$ and $2004(\mathrm{n}=604)$ for B. pertussis DFA and culture testing were used for the PCR validation study. These specimens were collected and submitted from clinics across Southern Alberta to the Provincial Laboratory for Public Health (ProvLab; Calgary, AB). Clinical data were not collected. Dacron NP swabs (Oxoid Inc., Nepean, ON) were received in either charcoal (Copan Diagnostics Inc., Corona, CA; $88 \%$ of the specimens) or Regan-Lowe (Daylnn Biologicals Inc., Calgary, AB; 12 \% of the specimens) transport media. The Regan Lowe medium contained cephalexin which would inhibit $B$. holmesii and prevent its identification by culture. Swabs were placed into $50 \mu \mathrm{l}$ of $1 \%(\mathrm{w} / \mathrm{v}$ ) casamino acid (Difco, Becton Dickison, Sparks, MD) diluted in PBS. The wire from the NP swab was cut and then, after brief vortexing to remove cellular material into the fluid, the swab was removed. The casamino acid volume was split for bacteriology (DFA/culture) and molecular testing (PCR). If a DFA slide was submitted in addition to the NP swab $20 \mu \mathrm{l}$ of the swab/casamino acid was used each for culture and PCR. If a DFA slide was not received with the patient swab, the casamino acid was split and $10 \mu \mathrm{l}$ of the swab/ casamino acid was used each for DFA, culture and PCR. Whether a slide for DFA was submitted or not, the volume of sample used for analysis by PCR or culture was always the same.

\section{DFA}

DFA testing was performed using a commercial monoclonal antibody reagent, according to the manufacturer's instructions (Accu-MAb ${ }^{\mathrm{TM}}$ Plus, Altachem Pharma Inc., Edmonton, $\mathrm{AB})$.

\section{Culture}

For culture, the 10 or $20 \mu \mathrm{l}$ of patient specimen was made up to $200 \mu \mathrm{l}$ with $1 \%$ casamino acid and split equally between two Regan-Lowe plates, one with and one without cephalexin (Daylnn). Cultures were held for 7 days and inspected daily. Opalescent colonies were gram stained. If gram negative rods or coccobacilli were seen a suspension of colony was prepared for identification using the fluorescein conjugated monoclonal antibody above.

\section{DNA extraction}

Nucleic acid was extracted from bacterial suspensions and clinical specimens using the automated MagNa Pure $\mathrm{LC}^{\mathrm{TM}}$ and DNA Isolation Kit I (Roche Diagnostics, Laval, QC). The 10 or $20 \mu$ of patient specimen was made up to 200 $\mu \mathrm{l}$ with physiological saline prior to extraction and elution was into $100 \mu \mathrm{l}$ volume. A negative control of $200 \mu \mathrm{l}$ saline was included. Ten $\mu$ of a B. pertussis control (ATCC 9797 at $10^{6} \mathrm{cfu} / \mathrm{ml}$ ) was made up to $200 \mu \mathrm{l}$ with saline and used as a positive extraction control.

\section{Primers and probes}

The primers used in all assays were prepared by the University of Calgary Core DNA Synthesis facility. The probes used in all assays were prepared by Applied BioSystems (Foster City, CA).

\section{IS48 I Hybridization probe assay}

Primers and probes used in the IS481 hybridization probe (IS481 HP) assay are as described previously [7]. Real- 
B.pertussis ATCC 9797

B.bronchiseptica AB 1254

B.bronchiseptica ATCC 786

B.bronchiseptica ATCC 19395

B.parapertussis KP92 \83\93

B.parapertussis KP92\437\93

B.parapertussis ATCC 15311

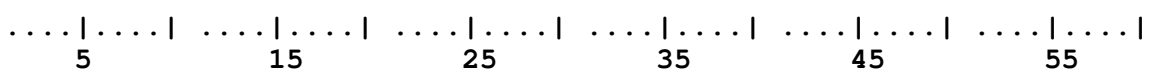

CGTCCGGCCG GCACCATCCC GCATACGTGT TGGCAACCGC CAACGCGCAT GCGTGCAGAT CGTCCGGCCG GCACCATCCC GCATACGTGT TGGCAACCGC CAACGCGTAT GCGCGCGGAT CGTCCGGCCG GCACCATCCC GCATACGTGT TGGCAACCGC CAACGCGTAT GCGCGCGGAT CGTCCGGCTG GCACCATCCC GCATACGTGT TGGCAACCGC CAACGCGTAT GCGCGCGGAT CGTCCGGCCG GCACCATCCC GCATACGTGT TGGCAACCGC CAACGCGTAT GCGCGCGGAT CGTCCGGCCG GCACCATCCC GCATACGTGT TGGCAACCGC CAACGCGTAT GCGCGCGGAT CGTCCGGCCG GCACCATCCC GCATACGTGT TGGCAACCGC CAACGCGTAT GCGCGCGGAT
B.pertussis ATCC 9797

B.bronchiseptica AB 1254

B.bronchiseptica ATCC 786

B.bronchiseptica ATCC 19395

B.parapertussis KP92 $\backslash 83 \backslash 93$

B.parapertussis KP92 \437\93

B.parapertussis ATCC 15311
B.pertussis ATCC 9797

B.bronchiseptica AB 1254

B.bronchiseptica ATCC 786

B.bronchiseptica ATCC 19395

B.parapertussis KP92 \83\93

B.parapertussis KP92 \437 \93

B.parapertussis ATCC 15311
B.pertussis ATCC 9797

B.bronchiseptica AB 1254

B.bronchiseptica ATCC 786

B.bronchiseptica ATCC 19395

B.parapertussis KP92 $\backslash 83 \backslash 93$

B.parapertussis KP92 $\backslash 437 \backslash 93$

B.parapertussis ATCC 15311

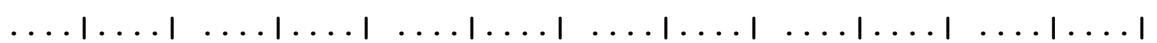

$$
\begin{array}{llllll}
65 & 75 & 85 & 95 & 105 & 115
\end{array}
$$

TCG -- - - ECGTACA AACCCTCGA TTCTTCCGTA CATCCCGCTA CTGCAATCCA GCG----- - - TCGCACA AAGCCCTCGA TTCTTCCGCA CATCCCGCTA CTGCAATCCA GCG----- ---TCGCACA AAGCCCTCGA TTCTTCCGCA CATCCCGCTA CTGCAATCCA GCGCGCGGAT GCGTCGCACA AAGCCCTCGA TCCTTCCGCA CATCCCGCTA CTGCAATCCA GCGCGCGGAT GCGTCGCACA AAGCCCTCAA TCCTTCCGCA CATCCCGCTA CTGTAATCCA GCGCGCGGAT GCGTCGCACA AAGCCCTCAA TCCTTCCGCA CATCCCGCTA CTGTAATCCA GCGCGCGGAT GCGTCGCACA AAgCCCTCAA TCCTTCCGCA CATCCCGCTA CTGTAATCCA

$$
\begin{array}{cccccc}
\ldots 1 \ldots 1 & \ldots 1 \ldots 1 & \ldots 1 \ldots 1 & \ldots 1 \ldots 1 & \ldots 1 & \ldots 1 \\
125 & 135 & 145 & 155 & 165 & 175
\end{array}
$$

ACACGGCATG AACGCTCCTT CGGCGCAAAg TCGCGCGATG GTACCGGTCA CCGTCCGGAC ACACGGCGCG AACGCTCCTT CGGCGCAAAG TCGCACGATG GTACCGGTCG CCGTCCAGAC ACACGGCGCG AACGCTCCTT CGGCGCAAAG TCGCACGATG GTACCGGTCG CCGTCCAGAC ACACGGCGCG AACGCCCCTT CGGCGCAAAG TCGCACGATG GTACCGGTCG CCGTCCGGAC ACACGGCGCA AACGCCCCTT CGGCGCAAAG TCGCACGATG GTACCGGTCG CCGTCCGGAC ACACGGCGCA AACGCCCCTT CGGCGCAAAG TCGCACGATG GTACCGGTCG CCGTCCGGAC ACACGGCGCA AACGCCCCTT CGGCGCAAAg TCGCACGATG GTACCGGTCG CCGTCCGGAC

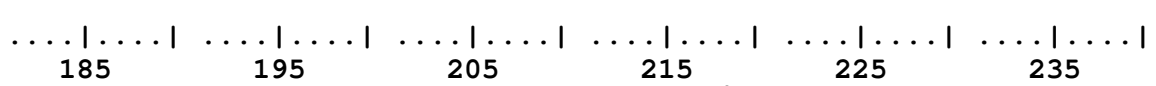

CGTGCTGACC CCCCTGCCAT GGTGTGA CC GTAAAATAGG CACCATCAAA ACGCAGAgGg TGTGCCGACC CCCCTGCCAT GGTGTGATCC GCAAAATAGg CGCCACCGAA ACGCAGAGGG TGTGCCGACC CCCCTGCCAT GGTGTGATCC GCAAAATAGg CGCCACCGAA ACGCAGAGGG CGTGCCGACC CCCCTGCCAT GGTGTGATCC GCACAATAGG CACCACGGAA ACGCAGAGGG CGTGCCGACC CCCCTGCCAT GGTGTGATCC GCAAAATAGG CGCCACAGAA ACGCAGAGGG CGTGCCGACC CCCCTGCCAT GGTGTGATCC GCAAAATAGG CGCCACAGAA ACGCAGAGGG CGTGCCGACC CCCCTGCCAT GGTGTGATCC GCAAAATAGG CGCCACAGAA ACGCAGAGGG

$$
\cdots+1 \ldots
$$

B.pertussis ATCC 9797

B.bronchiseptica AB 1254

B.bronchiseptica ATCC 786

B.bronchiseptica ATCC 19395

B.parapertussis KP92 $183 \backslash 93$

B.parapertussis KP92 \437\93

B.parapertussis ATCC 15311

\section{Figure I}

Alignment based on B. pertussis ATCC 9797 with primers and probe for real-time PCR indicated. The selected forward primer is labeled box I (base pairs 5I-69) the reverse primer as box 2 (base pairs 2I8-199) and the probe by box 3

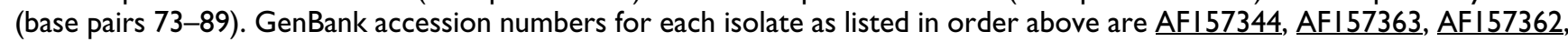
AFI57364, AFI57347, AFI57357, AFI5736I, respectively. 
time PCR was performed in a $20 \mu \mathrm{l}$ reaction mixture with final concentrations of $1 \mathrm{X}$ LightCycler ${ }^{\mathrm{TM}}$ FastStart DNA master hybridization probes mix (Roche Diagnostics), 3 $\mathrm{mM} \mathrm{MgCl}{ }_{2}, 0.5 \mu \mathrm{M}$ of each primer, $0.2 \mu \mathrm{M}$ of each hybridization probe and $5 \mu$ l of extracted template DNA. The amplification profile consisted of activation of enzyme at $95^{\circ} \mathrm{C}$ for $10 \mathrm{~min}$ followed by 50 cycles consisting of heating at $20^{\circ} \mathrm{C} / \mathrm{s}$ to $95^{\circ} \mathrm{C}$ with a 10 s hold, cooling at $20^{\circ} \mathrm{C} / \mathrm{s}$ to $50^{\circ} \mathrm{C}$ with a 10 s hold and heating at $20^{\circ} \mathrm{C} / \mathrm{s}$ to $72^{\circ} \mathrm{C}$ with a 10 s hold. Single fluorescent readings were taken at the annealing temperature $\left(55^{\circ} \mathrm{C}\right.$, once per cycle). Amplification, detection and data analysis were performed on the LightCycler ${ }^{\mathrm{TM}} 2.0$ with software version 4.0 (Roche Diagnostics).

\section{IS48 I and ISI00 I molecular beacon assays}

Primers and molecular beacons used in the IS481 and IS1001 molecular beacon (MB) assays are previously described [8]. The IS481 MB assay targets the IS481 region for detection of $B$. pertussis and B. holmesii and the IS1001 $\mathrm{MB}$ assay targets the IS1001 region for detection of $B$. parapertussis and B. holmesii.

These assays were originally designed for the iCycler (BioRad, Hercules, CA), but the assays were adapted for use on the LightCycler ${ }^{\mathrm{TM}}$ for the purposes of this study. Initial optimization involved testing a range of $\mathrm{MgCl}_{2}$ concentrations and varying annealing temperatures and cycling times in the amplification profile, using serial dilutions of purified B. pertussis (ATCC 9797), B. holmesii (ATCC 51541) and B. parapertussis (ATCC 1533) DNA.

The optimized IS481 MB assay was performed in a $20 \mu \mathrm{l}$ of reaction mixture with final concentrations of $1 \mathrm{X}$ LightCycler $^{\mathrm{TM}}$ FastStart DNA master hybridization probes mix, 3 $\mathrm{mM} \mathrm{MgCl}_{2}, 0.1 \mu \mathrm{M}$ of each primer, $0.3 \mu \mathrm{M}$ of the IS481 molecular beacon and $5 \mu \mathrm{l}$ of extracted template DNA. The optimized IS1001 MB assay was performed in $20 \mu \mathrm{l}$ of reaction mixture with final concentrations of $1 \mathrm{X}$ LightCycler $^{\mathrm{TM}}$ FastStart DNA master hybridization probes mix, 4.5 $\mathrm{mM} \mathrm{MgCl}{ }_{2}, 0.2 \mu \mathrm{M}$ of each primer, $0.4 \mu \mathrm{M}$ of the IS1001 molecular beacon and $5 \mu \mathrm{l}$ of extracted template DNA. The amplification profile for both assays consisted of activation of enzyme at $95^{\circ} \mathrm{C}$ for $10 \mathrm{~min}$ followed by 50 cycles consisting of heating at $20^{\circ} \mathrm{C} / \mathrm{s}$ to $95^{\circ} \mathrm{C}$ with a $5 \mathrm{~s}$ hold, cooling at $20^{\circ} \mathrm{C} / \mathrm{s}$ to $55^{\circ} \mathrm{C}$ with a $20 \mathrm{~s}$ hold, and heating at $10^{\circ} \mathrm{C} / \mathrm{s}$ to $72^{\circ} \mathrm{C}$ with a $15 \mathrm{~s}$ hold. Single fluorescent readings were taken at the annealing temperature $\left(55^{\circ} \mathrm{C}\right.$, once per cycle). Amplification, detection and data analysis were performed on the LightCycler ${ }^{\mathrm{TM}} 2.0$ with software version 4.0 .

\section{Development of a novel toxin promoter region (TPR) hydrolysis probe assay}

Selected sequences of the toxin promoter gene of $B$. pertussis with $100 \%$ homology in a 239 bp region were obtained from GenBank (accession numbers AF157344, $\underline{\mathrm{AF} 157344}, \underline{\mathrm{AF} 157332}, \underline{\mathrm{AF} 157342}, \underline{\mathrm{AF} 157341}, \underline{\mathrm{AF} 157340}$, AF157337), aligned and a consensus sequence determined (BioEdit, version 7.0.1, Isis Pharmaceuticals Inc., Carlsbad, CA). This consensus was then aligned with 3 different strains of $B$. parapertussis and B. bronchiseptica to determine significant polymorphic regions (Figure 1). Primers and a probe were designed from the $B$. pertussis consensus sequence using PrimerExpress software (Applied BioSystems, Foster City, CA) with some adaptations to incorporate the polymorphic regions. The probe was designed with a FAM fluorescent reporter on the 5' end and non-fluorescent black hole quencher (BNFQ) at the 3 ' end. PrimerExpress was used to ensure minimal self-complementary and secondary structures for primers and probe. A BLAST search of available sequences in the GenBank database was performed to verify the specificity of the primers and probe. Several primer pairs were tested by conventional PCR to determine the combination of forward and reverse primers that performed optimally. The primer pair that was finally chosen for conventional and real-time PCR amplified a 167 bp region. Sequences of optimized primers and hydrolysis probe were as follows:

Forward TPR primer 5'GCGTGCAGATTCGTCGTAC3'

Reverse TPR primer 5'TGATGGTGCCTATTTTACGG3'

Hydrolysis (TaqMan) TPR probe 5'FAM-ACCCTCGATTCTTCCGT-BNFQ3'

Conventional PCR was performed in $50 \mu$ l of reaction mixture with final concentrations of 1X PCR buffer (Invitrogen Canada Inc., Burlington, ON), $2 \mathrm{mM} \mathrm{MgCl}_{2}, 0.1$ $\mathrm{mM}$ of each dNTP (Invitrogen), $0.4 \mu \mathrm{M}$ of each primer, $1.25 \mathrm{U}$ of DNA Taq polymerase (Invitrogen) and $5 \mu \mathrm{l}$ of extracted template DNA. The amplification profile consisted of an initial incubation of $3 \mathrm{~min}$ at $95^{\circ} \mathrm{C}$ followed by 40 cycles of $30 \mathrm{~s}$ at $95^{\circ} \mathrm{C}, 30 \mathrm{~s}$ at $55^{\circ} \mathrm{C}$ and $30 \mathrm{~s}$ at $72^{\circ} \mathrm{C}$, with a final $10 \mathrm{~min}$ hold at $72^{\circ} \mathrm{C}$. The $167 \mathrm{bp} \mathrm{B}$. pertussis product was separated by agarose gel electrophoresis ( $2 \%$ agarose containing $0.5 \mu \mathrm{g} / \mathrm{ml}$ ethidium bromide in $0.5 \times$ TBE buffer). Amplified products were viewed and photographed under UV light.

The real-time TPR assay was performed on the LightCycler $^{\mathrm{TM}}$ with a variety of $\mathrm{MgCl}_{2}$, primers and probe concentrations. The optimized reaction was undertaken in a 20 $\mu \mathrm{l}$ reaction mixture with final concentrations of $1 \mathrm{X}$ LightCycler FastStart DNA master hybridization probes mix, 3 


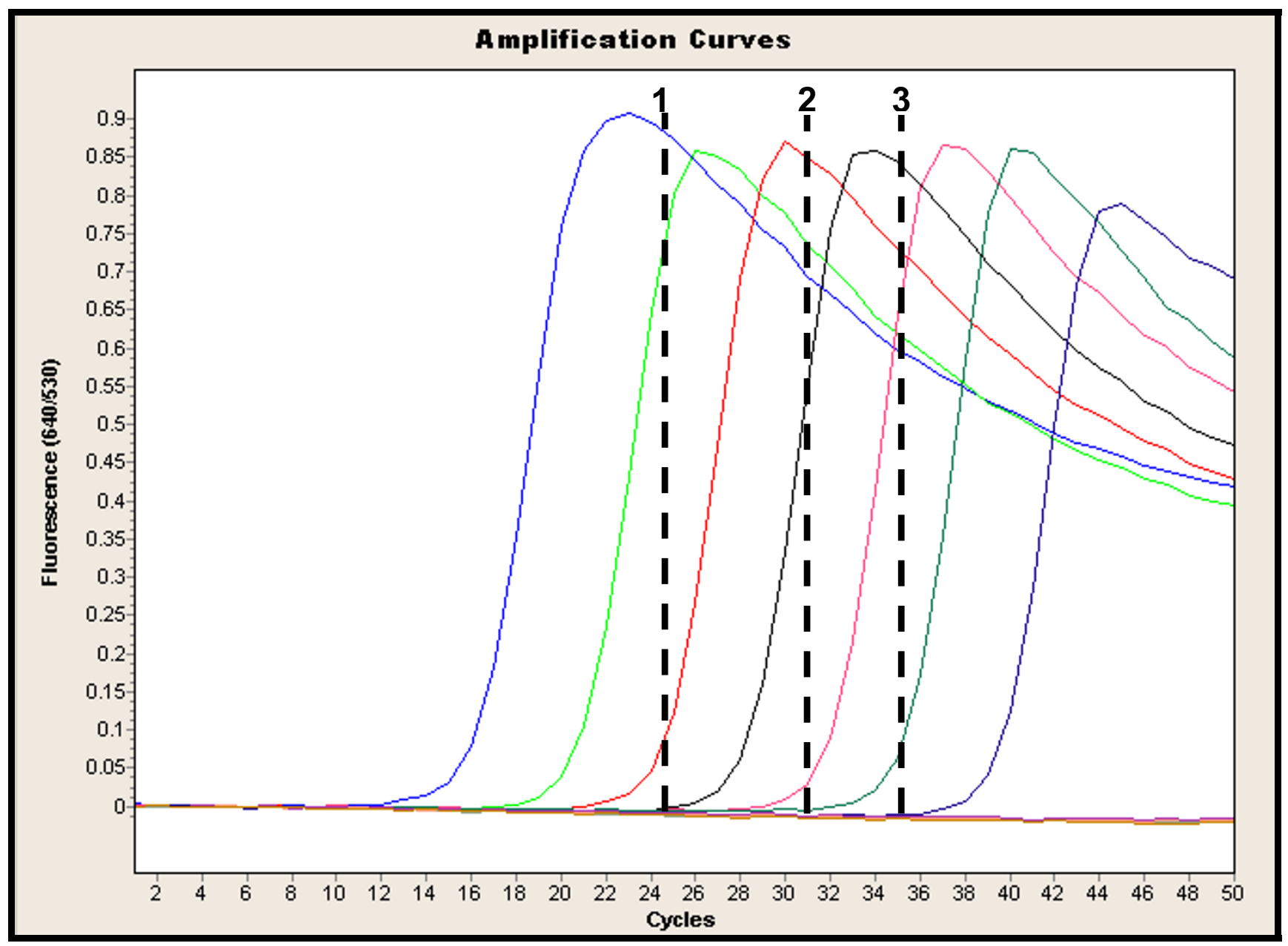

Figure 2

LightCycler $^{\mathrm{TM}}$ amplification profile of the IS48 I HP probe assay with a dilution series of B. pertussis ATCC 9797 strain of $B$. pertussis was utilized $\left(10^{6} \mathrm{cfu} / \mathrm{ml}\right.$ to $\left.10^{-3} \mathrm{cfu} / \mathrm{ml}\right)$. Analytical sensitivity of this assay is $10 \mathrm{cfu} / \mathrm{ml}(0.1 \mathrm{cfu}$ input). The dashed lines correspond to the average $C t$ value where conventional results are: $I=D F A$ positive and culture positive, $2=$ DFA negative, culture positive, $3=$ DFA negative, culture negative. $\mathrm{HP}=$ hybridization probe, $\mathrm{Ct}=\mathrm{crossing}$ threshold, $\mathrm{DFA}=$ direct fluorescent antigen

$\mathrm{mM} \mathrm{MgCl}{ }_{2}, 0.5 \mu \mathrm{M}$ each primer, $0.1 \mu \mathrm{M}$ probe, and $5 \mu \mathrm{l}$ of extracted template DNA. The amplification profile consisted of activation of enzyme at $95^{\circ} \mathrm{C}$ for $10 \mathrm{~min}$ followed by 50 cycles consisting of heating at $20^{\circ} \mathrm{C} / \mathrm{s}$ to $95^{\circ} \mathrm{C}$ with a $5 \mathrm{~s}$ hold, cooling at $20^{\circ} \mathrm{C} / \mathrm{s}$ to $55^{\circ} \mathrm{C}$ with a 20 $\mathrm{s}$ hold and heating at $10^{\circ} \mathrm{C} / \mathrm{s}$ to $72^{\circ} \mathrm{C}$ with a $15 \mathrm{~s}$ hold. Single fluorescent readings were taken at the annealing temperature $\left(55^{\circ} \mathrm{C}\right.$, once per cycle $)$. Amplification, detection and data analysis were performed on the LightCycler $^{\mathrm{TM}} 2.0$ with software version 4.0 .

\section{Reporting of results and data analysis}

For this laboratory based study a positive result for any PCR or culture-based assay was considered a "true positive" for analysis. Only conventional DFA and culture were reported to submitting physicians during this study period.

\section{Results}

Analytical sensitivity and specificity of the IS48 I HP assay The IS481 HP assay was performed on a serial dilution of purified DNA of $B$. pertussis ATCC 9797 to determine the limit of detection for this assay. This assay gave a good positive signal from $10 \mathrm{cfu} / \mathrm{ml}$ stock reproducibly (equivalent to $0.1 \mathrm{cfu}$ input into the assay; Figure 2). The $1 \mathrm{cfu} /$ $\mathrm{ml}$ stock (input $0.01 \mathrm{cfu} / \mathrm{ml}$ ) gave a positive result in approximately $20 \%$ of tests. The same positive control stock preparation was used as the processed positive control in the validation study, at $5000 \mathrm{cfu} / \mathrm{ml}$ and had an average Ct value of $26.0( \pm 2.0)$ cycles. This corresponds 


\section{9 negative by all assays}

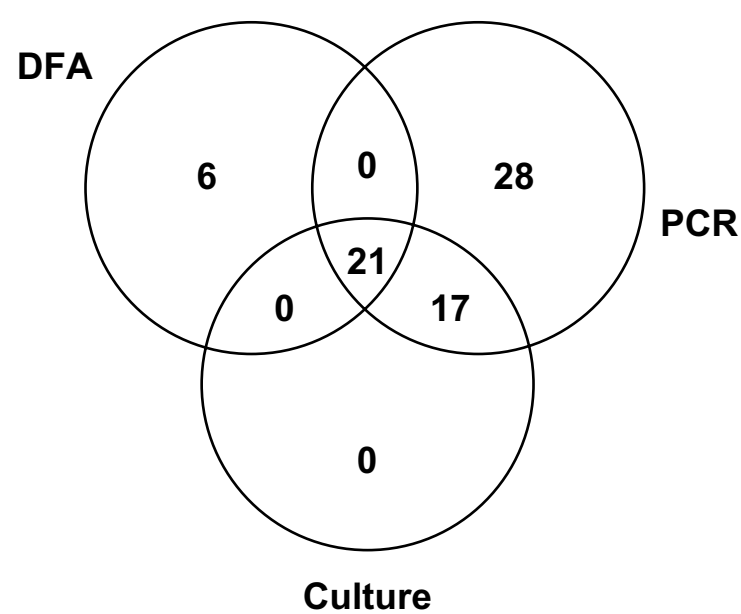

Figure 3

Correlation of positive results for specimens tested by DFA, culture and the IS48 I HP PCR assay for B. pertussisw HP = hybridization probe, DFA = direct fluorescent antigen Seven specimens were overgrown in culture and thus have not been included in the Figure (see text for details).

to an inter-assay coefficient of variation of approximately $8 \%$ for this control. As expected, this assay picked up $B$. holmesii as well as B. pertussis but not B. parapertussis [7]. Further assessment of specificity for this assay was not undertaken but has been evaluated elsewhere [7].

\section{Comparison of the IS48 I HP assay with conventional methods}

A total of 808 specimens were tested by PCR for B. pertussis during this study between March 2003 and April 2004 (204 specimens from 2003 and 604 from 2004). Figure 3 summarizes the results and Table 1 shows the average crossing threshold (Ct) and standard deviation (SD) for positive specimens for each combination of results.

Of the 808 samples tested, 729 were negative by all 3 methods. Nine contained detectable IS481 target DNA in a single run but results were not reproducible and finally were reported as not containing detectable $B$. pertussis. These specimens were weakly positive [average Ct of 38.1 ( \pm 2.3 ) cycles]. DFA had poor sensitivity, missing 17 samples that were positive by both culture and the IS481 HP assay, as well as 28 samples that were positive by the IS481 HP assay, but negative by culture. Six specimens that were
DFA positive, tested negative by both culture and PCR and are most likely false positives due to the subjective nature of DFA interpretation. Seven specimens were overgrown in culture, 4 of which were negative by PCR and DFA and 3 were positive by PCR ( 1 of these 3 was positive by DFA).

\section{Comparison of real-time PCR methods for the detection of} $B$. pertussis and $B$. holmesii

The analytical sensitivity of the IS481 MB assay was determined using a serial dilution of purified DNA of $B$. pertussis ATCC 9797 with a detection limit of $10 \mathrm{cfu} / \mathrm{ml}(1 \mathrm{cfu}$ input) which is similar to that reported previously [8]. Thus a 10-fold difference in end point sensitivity was noted when compared with the IS481 HP assay. The IS481 $\mathrm{MB}$ assay gave average $\mathrm{Ct}$ values 4-5 cycles higher for positive patient specimens than the IS481 HP assay (Table 1).

The IS481 MB and IS1001 MB assays [8] utilize primers and probes that amplify and detect a 154 bp fragment in the IS481 region specific to B. pertussis and B. holmesii (Figure 4 ) and a 186 bp region in the IS1001 region, specific to $B$. parapertussis and B. holmesii (Figure 5), respectively. Combined results from both reactions can resolve whether a specimen is positive for $B$. pertussis, B. parapertussis or B. holmesii. In our experiments, the IS1001 primers gave a non-specific product of approximately $700 \mathrm{bp}$ for two $B$. bronchiseptica strains, but this product was not recognized by the $\mathrm{MB}$ probe (Figure 5). Further assessment of specificity for this assay was not undertaken during this study but has been evaluated elsewhere [8].

Several previously extracted patient samples were retested by the IS481 HP assay to ensure the integrity of the extracted DNA over time (data not shown). Eleven positive specimens with an average $\mathrm{Ct}$ value of $25.2( \pm 4.8)$ cycles on the original PCR run, remained positive with an average Ct value of 25.9 ( \pm 5.1 ). This difference was considered insignificant, indicating that the DNA in these specimens had not degraded over time, and that subsequent retesting with the IS481 MB and IS1001 MB assays for comparison was valid.

All 66 samples positive by the IS481 HP assay were retested by both the IS481 MB and IS1001 MB assays. Table 1 compares these 66 specimens in relation to PCR and conventional results, including average $\mathrm{Ct}$ values $( \pm$ SD). Sixty-four of $66(93.0 \%)$ of these samples confirmed positive for $B$. pertussis by the IS481 MB assay. The 2 samples that did not confirm were weak positives as they were also missed by both DFA and culture and had high Ct values on the IS481 HP assay (39.7and 39.1 cycles). No B. holmesii was detected in this population by the IS1001 MB assay. A random selection of 29 samples that were negative by the IS481 HP assay were also screened by the IS481 and IS1001 MB assays. No further positives were obtained 
Table I: Comparison of positive B. pertussis patient specimens by real-time RT-PCR assays Average crossing threshold (Ct) values and standard deviations (SD) for each combination of PCR and conventional results are shown. Samples were selected based on results for DFA/culture IS48I HP PCR.

\begin{tabular}{|c|c|c|c|c|c|c|c|c|c|}
\hline \multirow{2}{*}{$\begin{array}{c}\text { Result } \\
\text { combination }\end{array}$} & \multicolumn{3}{|c|}{ IS48I HP Assay } & \multicolumn{3}{|c|}{ IS48I MB Assay* } & \multicolumn{3}{|c|}{ TPR Assay* } \\
\hline & $\begin{array}{l}\text { Positive/ } \\
\text { tested (\%) }\end{array}$ & $\begin{array}{l}\text { Average } C t \text { of } \\
\text { positives }\end{array}$ & SD of positives & $\begin{array}{l}\text { Positivel } \\
\text { tested (\%) }\end{array}$ & $\begin{array}{c}\text { Average } C t \text { of } \\
\text { positives }\end{array}$ & SD of positives & $\begin{array}{l}\text { Positivel } \\
\text { tested (\%) }\end{array}$ & $\begin{array}{l}\text { Average } C t \text { of } \\
\text { positives }\end{array}$ & SD of positives \\
\hline $\begin{array}{l}\text { DFA negative } \\
\text { Culture negative } \\
\text { Screen PCR } \\
\text { (IS48/HP) positive }\end{array}$ & $28 / 28(100.0)$ & 35.7 & 3.9 & $26 / 28(92.9)$ & 40.4 & 3.2 & $15 / 28(53.6)$ & 40.1 & 2.1 \\
\hline $\begin{array}{l}\text { DFA negative } \\
\text { Culture positive } \\
\text { Screen PCR } \\
\text { (IS48IHP) positive }\end{array}$ & $17 / 17(100.0)$ & 31.6 & 5.4 & $17 / 17(100.0)$ & 36.5 & 5.7 & I5/17 (88.2) & 37.7 & 5.0 \\
\hline $\begin{array}{l}\text { DFA positive } \\
\text { Culture positive } \\
\text { Screen PCR } \\
\text { (IS48IHP) positive }\end{array}$ & $21 / 21(100.0)$ & 24.9 & 3.8 & $21 / 21(100.0)$ & 30.1 & 3.9 & $21 / 21(100.0)$ & 32.3 & 3.4 \\
\hline
\end{tabular}

*In cases where cycle results were $>45,45$ was used to calculate average $\mathrm{Ct}$ values and $\mathrm{SD}$. HP $=$ hybridization probe, $\mathrm{MB}=$ molecular beacon, $\mathrm{TPR}=$ toxin promoter region, $\mathrm{DFA}=$ direct fluorescent antigen. 


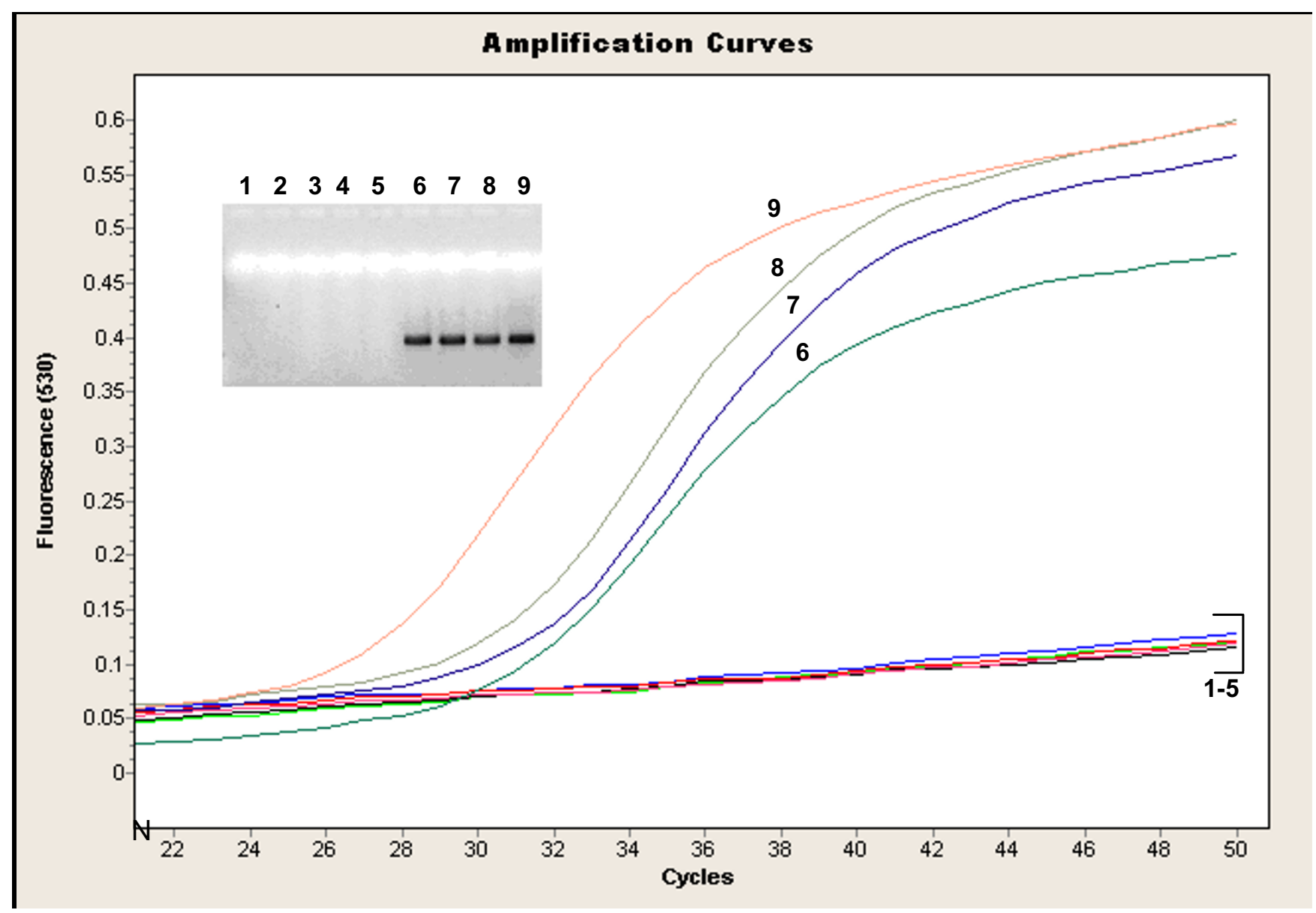

\section{Figure 4}

LightCycler ${ }^{\mathrm{TM}}$ amplification profile of the IS48 I MB assay with Bordetella isolates The samples correspond to: I = $B$. bronchiseptica ATCC 10580, 2 = B. bronchiseptica ATCC 295 I 3, $3=$ B. parapertussis ATCC I533, $4=$ B. parapertussis 33047, $5=$ B. parapertussis 33205, 6 = B. holmesii ATCC 5I54I, $7=$ B. holmesii 98PI 995-F, $8=$ B. holmesii 98P097I-D, $9=$ B. pertussis ATCC 9797. The specific amplified product is $154 \mathrm{bp}$ and the agarose gel of products is given as an inlay (numbers correspond to samples in the amplification curves). Stocks of Bordetella isolates were approximately $10^{6} \mathrm{cfu} / \mathrm{ml}$ unless otherwise quoted. $\mathrm{MB}=$ molecular beacon

by the IS481 MB assay but 2 specimens that were culture positive for B. parapertussis were detected by the IS1001 $\mathrm{MB}$ assay, as expected.

\section{TPR hydrolysis probe assay}

This novel real-time PCR assay showed high specificity for $B$. pertussis and did not pick up cultured B. holmesii, B. bronchiseptica or B. parapertussis (Figure 6). Analytical sensitivity of this assay was performed on a serial dilution of purified DNA of B. pertussis ATCC 9797 and detected 100 $\mathrm{cfu} / \mathrm{ml}$, a 10-100 -fold difference from the IS481 HP and IS481 MB assays. No difference in limit of detection was noted whether analysis of amplified products was by agarose gel electrophoresis or using the TPR probe. Thus the difference in sensitivity when comparing this assay to those targeting insertion sequences was more likely related to the difference in template copy number than design of the probe. The conventional assays targeting TPR (used in the developmental stages of the final realtime assay) gave the same limit of detection when analysed by agarose gel electophoresis as products from the LightCycler ${ }^{\mathrm{TM}}$ assay $(1000 \mathrm{cfu} / \mathrm{ml}$ stock concentration or $10 \mathrm{cfu}$ input into the assay). Interestingly, one of the $B$. holmesii isolates gave two higher molecular weight bands than the expected specific product when analyzed by agarose gel electrophoresis (lane 13 from gel inlay of Figure $6)$. These products were not picked up by the specific probe, however.

All 66 samples positive by the IS481 HP assay were retested by the TPR assay (Table 1 ). The TPR assay was able to detect $100 \%$ of the specimens where the IS481 HP 


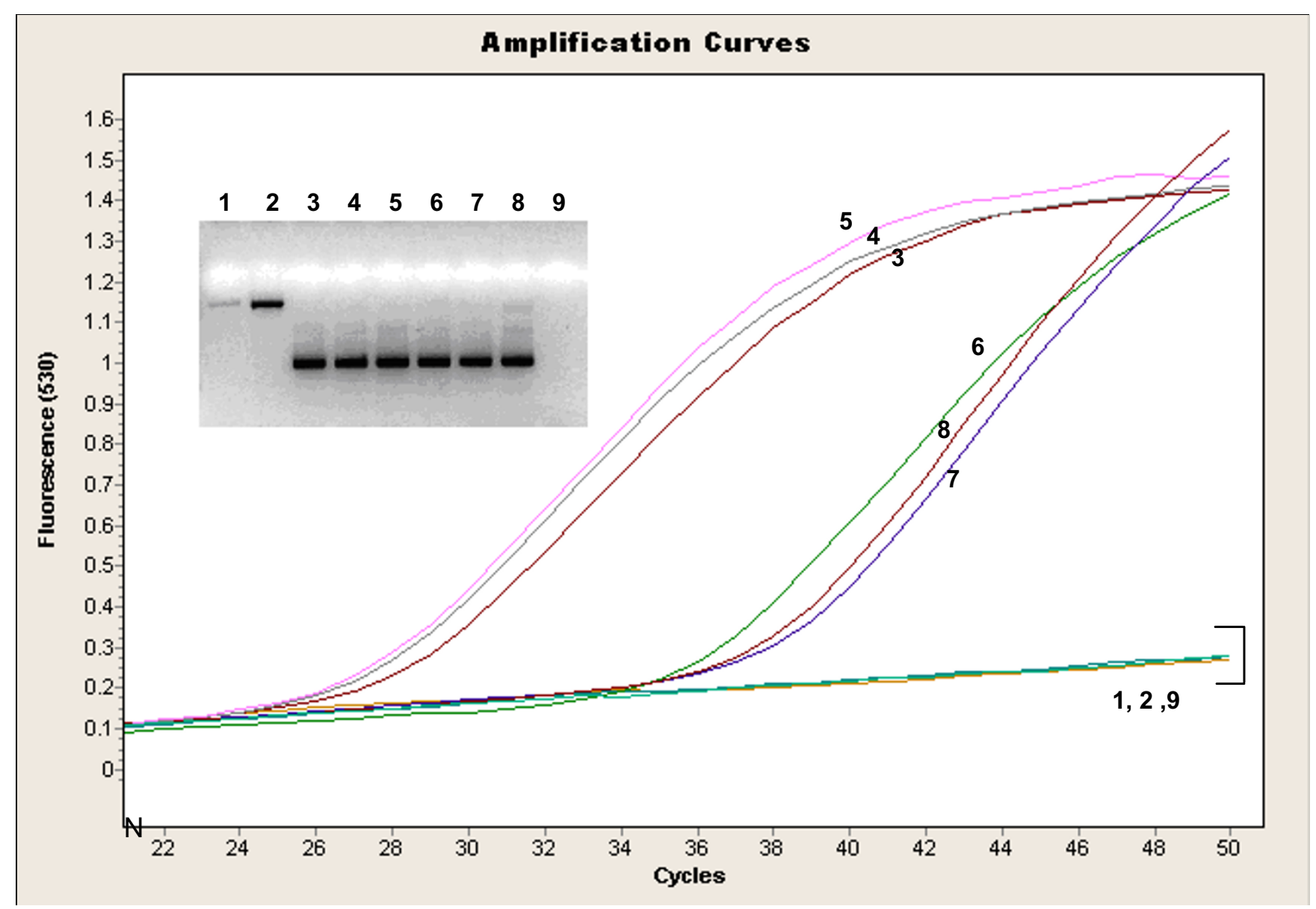

Figure 5

LightCycler ${ }^{\mathrm{TM}}$ amplification profile of the ISIO0I MB assay with Bordetella isolates The samples correspond to: I = B. bronchiseptica ATCC I0580, 2 = B. bronchiseptica ATCC 295I 3, 3 = B. parapertussis ATCC I533, $4=$ B. parapertussis 33047, 5 = B. parapertussis 33205, $6=$ B. holmesii ATCC 5I 54I, $7=$ B. holmesii 98PI 995-F, $8=$ B. holmesii 98P097I-D, 9= B. pertussis ATCC 9797 . The specific amplified product is $186 \mathrm{bp}$ and the agarose gel of products is given as an inlay (numbers correspond to samples in the amplification curves). $M B=$ molecular beacon.

assay, IS481 MB assay, culture and DFA were all positive. The sensitivity of this assay decreased slightly where DFA was unable to detect positives. Sensitivity was 50\% for specimens which were culture negative but IS481 HP assay positive.

Patient data collected after this study (June to October 2004) remained consistent with the results presented above (data not shown). B. pertussis was detected in approximately $10 \%$ of the specimens and $B$. holmesii was absent (using the IS1001 MB assay). Of the 16 positive specimens detected by the IS481 HP assay (from a total of 131 tested), all were detected by the IS481 MB assay, and 12 were detected by the TPR assay. The 4 positives that the TPR assay missed were weak positives with high $\mathrm{Ct}$ values on the IS481 HP and IS481 MB assays.

\section{Discussion}

PCR has been shown to be more sensitive than culture, resulting in culture negative/PCR positive specimens [2,914]. Only a few studies have reported cases of culture positive/PCR negative samples and most of these were earlier papers with interpretation of results complicated by the following factors: unequal sample splitting, lack of DNA extraction procedures, inhibited PCR reactions and/or lack of sensitive product detection methods.

Real-time PCR assays with IS481 have been published [68,15-18]. Advantages offered by real-time PCR include; elimination of post-amplification handling thereby reducing the risk of contamination, faster turn-around time and higher sensitivity [8]. We were able to confirm in this study the diagnostic utility of the previously published methods, adapt alternative assays targeting inser- 


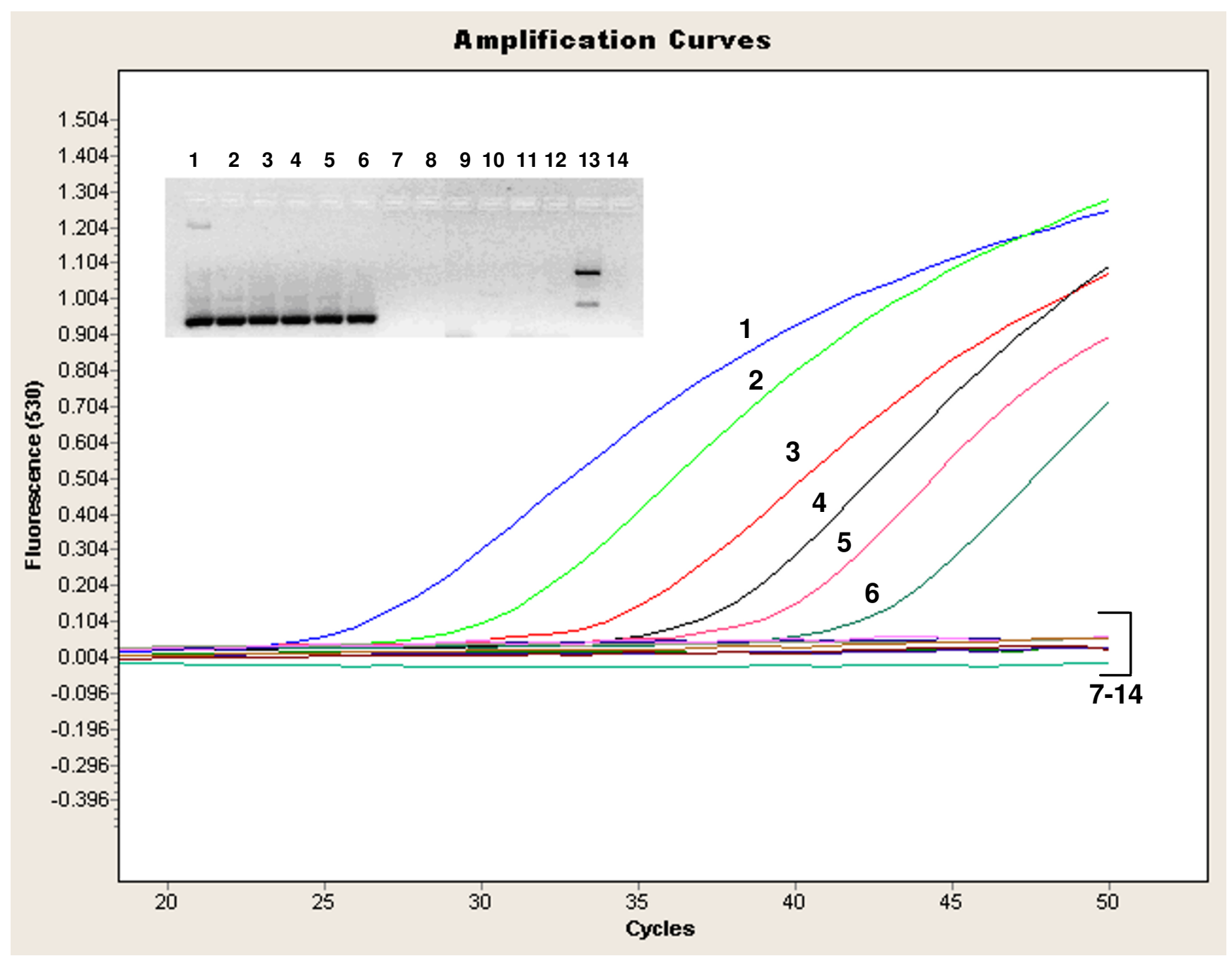

Figure 6

LightCycler ${ }^{\mathrm{TM}}$ amplification profile of the TPR assay with Bordetella isolates. The samples correspond to: $\mathrm{I}-8=$ dilution series of $B$. pertussis ATCC $9797\left(10^{8} \mathrm{cfu} / \mathrm{ml}\right.$ to $10^{1} \mathrm{cfu} / \mathrm{ml}$, respectively), $9=B$. bronchiseptica ATCC I0580, $10=B$. bronchiseptica ATCC 295 I3, II = B. parapertussis ATCC I533, I2 = B. parapertussis 33047, I3 = B. holmesii ATCC 5 I 54I, I4 = B. holmseii 98P 1995. The amplified product is 167 bp and the agarose gel of products is given as an inlay (numbers corresponding to samples in the amplification curves). Stocks of Bordetella isolates were approximately $10^{6} \mathrm{cfu} / \mathrm{ml}$ unless otherwise quoted.

tion sequences to rapid LightCycler ${ }^{\mathrm{TM}}$ format for confirmation of positive results, as well as design and develop an assay based on TPR for B. pertussis. In our study, the IS481 HP assay increased the yield of B. pertussis positive nasopharyngeal swabs by 1.7 fold (detecting 28 positives in addition to the 38 detected with culture). None of the specimens were culture positive/PCR negative. The IS481 HP and IS481 MB assays had analytical sensitivities of $1-10 \mathrm{cfu} / \mathrm{ml}(0.1-1 \mathrm{cfu}$ input $)$, which is consistent with previously published data [8].

A problem that we encountered with the IS481 HP assay was weak positives with high crossing thresholds ("high cycle positives") that were irreproducible with a second run of the same IS481 HP assay and/or with the IS481 MB assay. These were reported as not containing detectable pertussis DNA. It is unknown whether this type of result represents very low levels of $B$. pertussis in the specimen or a false positive signal.

One concern is that culture negative/PCR positive specimens may represent false positive PCR reactions rather than increased PCR sensitivity. As a first check for possible false positive reactions, we utilized assays targeting different regions of IS481 (the IS481 HP and IS481 MB assays) with good concordance for positive results. A further approach we used to help interpret IS481 positive results was to perform PCR against a different target gene (toxin 
promoter). If both gene target assays (against IS481 and toxin promoter) are positive, then it is reasonable to conclude that the specimen is truly $B$. pertussis positive. We developed a novel real-time PCR targeting the TPR for use as a second target to IS481. Currently there is no sequence available in GenBank for the TPR of $B$. holmesii, which presented a challenge in developing this assay. However, due to the sequence heterogeneity among other Bordetella species, we were able to design a highly $B$. pertussis-specific assay. We tested the specificity of the toxin promoter primers with isolates of $B$. parapertussis, B. bronchiseptica and $B$. holmesii. Even large amounts of DNA from these organisms failed to give false positive results using this assay. The TPR PCR had an analytical sensitivity of 1000 $\mathrm{cfu} / \mathrm{ml}$ (10 cfu input) and is thus less sensitive than the assays targeting the IS481 region. This is in agreement with previous data [6] and is explained by the gene copy number of 50-100 for IS481 compared to 1 for the toxin promoter. We recognized that sensitivity would be a limiting factor of the toxin promoter target. Among the 66 specimens that were positive by the IS481 HP assay, there were 51 that also gave positive results with the TPR PCR. Of the 15 that did not confirm, 2 were culture positive and therefore represent false negatives with the TPR assay, which could possibly be due its poorer sensitivity or due to a polymorphism of the toxin promoter [19]. Thus, even with its 100 fold-lower analytical sensitivity, the TPR PCR was useful for confirming the majority of specimens.

The IS481 target for $B$. pertussis diagnosis has the limitation of also being present in $B$. holmesii $[7,13,20]$ and some B. bronchiseptica strains (ATCC 4617, ATCC 14455) [9]. The IS481 sequence of B. holmesii and B. pertussis differs by only 2 bases [7]. One approach to decipher whether a specimen positive for IS481 is B. pertussis versus $B$. holmesii is to perform the IS1001 MB assay [8]. B holmesii contains the IS1001 but B. pertussis does not. B holmesii was not detected in any of our NP specimens, which suggests that it may not be unnecessary to rule out $B$. holmesii for specimens that are positive for IS481 in the Alberta population. Our study did not include B. bronchiseptica ATCC 4617 or ATCC 14455 but this warrants further study. Interestingly, the IS1001 primers gave a product for B. bronchiseptica ATCC 29513 and ATCC 10580, which has not been previously reported. This product was not recognized by the MB probe, demonstrating the specificity provided by the probe.

Although PCR is a useful tool for B. pertussis diagnosis, it is still important to obtain isolated $B$. pertussis organisms for epidemiologic characterization. We found that both culture and PCR could be undertaken from a single NP swab. Elution of the swab in casamino acid allowed equal splitting of the specimen for DFA or culture and PCR, thereby removing sampling bias in the interpretation of results.

\section{Conclusion}

In summary, the results of this study confirm that PCR is more sensitive than culture and DFA for diagnosis of $B$. pertussis. As a result of this work our laboratory has discontinued DFA and reports only IS481 HP PCR results to submitters. Specificity of reproducible positive specimens is $100 \%$ and $B$. holmesii is not prevalent in our population. We have been able to show that PCR is a suitable and practical approach to $B$. pertussis detection and diagnosis, providing rapid results, which are useful for management of individuals and potential outbreaks. We have explored use of additional tests in order to differentiate B. pertussis from closely related organisms, which may present with similar symptoms. Currently, all NP swabs are tested using the IS481 HP assay, and positive specimens are cultured. The IS481 MB assay is employed for specimens that are difficult to resolve using the IS481 HP assay and as a second line test. Retrospectively, patient samples are batched and tested by the IS1001 MB and TPR assays for research purposes and to ensure there are no changes in $B$. holmesii incidence in the population. The screening PCR assay is more sensitive than the other procedures, and its specificity is acceptable. Culture is maintained for PCRpositive specimens only, for epidemiologic purposes. Our follow up procedures confirm the validity of the front-line PCR test for $B$. pertussis in our laboratory.

\section{Competing interests}

The author(s) declare that they have no competing interests.

\section{Authors' contributions}

LK undertook the experiments for this study and prepared the draft methods and results sections of the manuscript. JA-B evaluated sample collection and storage and drafted the introduction and discussion of results for the manuscript. PT and JF were equally involved in the conception and design of the study as well as critical appraisal and revision of the manuscript. All authors read and approved the final manuscript.

\section{Acknowledgements}

B. holmesii isolates were graciously provided by $\mathrm{Dr} \mathrm{H}$ George, Massachusetts State Laboratory Institute, Boston, Massachusetts. Technologists in Molecular Diagnostics and Bacteriology (Calgary ProvLab) provided excellent technical assistance for this project.

\section{References}

I. Heininger U, Stehr K, Schmitt-Grohe S, Lorenz C, Rost R, Christenson PD, uberall M, Cherry JD: Clinical characteristics of illness caused by Bordetella parapertussis compared with illness caused by Bordetella pertussis. Pediatr Infect Dis J 1994, 13:306-309.

2. Woolfrey BF, Moody JA: Human infections associated with Bordetella bronchiseptica. Clin Microbiol Rev 199I, 4:243-255. 
3. Mazengia E, Silva EA, Peppe JA, Timperi R, George H: Recovery of Bordetella holmesii from patients with pertussis-like symptoms: use of pulsed-field gel electrophoresis to characterize circulating strains. J Clin Microbiol 2000, 38:2330-2333.

4. Yih WK, Silva EA, Ida J, Harrington N, Lett SM, George H: Bordetella holmesii-like organisms isolated from Massachusetts patients with pertussis-like symptoms. Emerg Infect Dis 1999, 5:44|-443.

5. Houard S, Hackel C, Herzog A, Bollen A: Specific identification of Bordetella pertussis by the polymerase chain reaction. Res Microbiol 1989, I40:477-487.

6. Sloan LM, Hopkins MK, Mitchell PS, Vetter EA, Rosenblatt JE, Harmsen WS, Cockerill FR, Patel R: Multiplex LightCycler PCR assay for detection and differentiation of Bordetella pertussis and Bordetella parapertussis in nasopharyngeal specimens. J Clin Microbiol 2002, 40:96-100.

7. Reischl U, Lehn N, Sanden GN, Loeffelholz MJ: Real-time PCR assay targeting IS48 I of Bordetella pertussis and molecular basis for detecting Bordetella holmesii. J Clin Microbiol 200I, 39:1963-1966.

8. Templeton KE, Scheltinga SA, van der ZA, Diederen BM, van Kruijssen AM, Goossens H, Kuijper E, Claas EC: Evaluation of real-time PCR for detection of and discrimination between Bordetella pertussis, Bordetella parapertussis, and Bordetella holmesii for clinical diagnosis. J Clin Microbiol 2003, 4I:4I2I-4I 26.

9. Cloud JL, Hymas WC, Turlak A, Croft A, Reischl U, Daly JA, Carroll KC: Description of a multiplex Bordetella pertussis and Bordetella parapertussis LightCycler PCR assay with inhibition control. Diagn Microbiol Infect Dis 2003, 46: 189-195.

10. Farrell DJ, Daggard G, Mukkur TK: Nested duplex PCR to detect Bordetella pertussis and Bordetella parapertussis and its application in diagnosis of pertussis in nonmetropolitan Southeast Queensland, Australia. J Clin Microbiol 1999, 37:606-610.

II. Grimprel E, Begue P, Anjak I, Betsou F, Guiso N: Comparison of polymerase chain reaction, culture, and western immunoblot serology for diagnosis of Bordetella pertussis infection. J Clin Microbiol 1993, 3 I:2745-2750.

12. He Q, Mertsola J, Soini H, Skurnik M, Ruuskanen O, Viljanen MK: Comparison of polymerase chain reaction with culture and enzyme immunoassay for diagnosis of pertussis. J Clin Microbiol 1993, 31:642-645.

13. Loeffelholz MJ, Thompson CJ, Long KS, Gilchrist MJ: Detection of Bordetella holmesii using Bordetella pertussis IS48I PCR assay. I Clin Microbiol 2000, 38:467.

14. van der ZA, Agterberg C, Peeters M, Mooi F, Schellekens J: A clinical validation of Bordetella pertussis and Bordetella parapertussis polymerase chain reaction: comparison with culture and serology using samples from patients with suspected whooping cough from a highly immunized population. J Infect Dis 1996, 174:89-96.

15. Kosters K, Riffelmann M, Wirsing von Konig CH: Evaluation of a real-time PCR assay for detection of Bordetella pertussis and B. parapertussis in clinical samples. J Med Microbiol 200I, 50:436-440.

16. Kosters K, Reischl U, Schmetz J, Riffelmann M, Wirsing von Konig $\mathrm{CH}$ : Real-time LightCycler PCR for detection and discrimination of Bordetella pertussis and Bordetella parapertussis. J Clin Microbiol 2002, 40: 17I9-I722.

17. Poddar SK, Le CT: Bordetella pertussis detection by spectrofluorometry using polymerase chain reaction (PCR) and a molecular beacon probe. Mol Cell Probes 200I, 15:16I-167.

18. Poddar SK: Detection and discrimination of $\mathbf{B}$ pertussis and $B$ holmesii by real-time PCR targeting IS48 I using a beacon probe and probe-target melting analysis. Mol Cell Probes 2003, 17:91-98.

19. Nygren M, Reizenstein E, Ronaghi M, Lundeberg J: Polymorphism in the pertussis toxin promoter region affecting the DNAbased diagnosis of Bordetella infection. J Clin Microbiol 2000, 38:55-60.

20. Lind-Brandberg L, Welinder-Olsson C, Lagergard T, Taranger J, Trollfors B, Zackrisson G: Evaluation of PCR for diagnosis of Bordetella pertussis and Bordetella parapertussis infections. J Clin Microbiol 1998, 36:679-683.

\section{Pre-publication history}

The pre-publication history for this paper can be accessed here:

http://www.biomedcentral.com/1471-2334/6/62/prepub
Publish with Biomed Central and every scientist can read your work free of charge

"BioMed Central will be the most significant development for disseminating the results of biomedical research in our lifetime. "

Sir Paul Nurse, Cancer Research UK

Your research papers will be:

- available free of charge to the entire biomedical community

- peer reviewed and published immediately upon acceptance

- cited in PubMed and archived on PubMed Central

- yours - you keep the copyright
BioMedcentral 